\title{
Thermal shock and fatigue behavior of pressureless sintered $\mathrm{Al}_{2} \mathrm{O}_{3}-\mathrm{SiO}_{2}-\mathrm{ZrO}_{2}$ composites
}

\author{
G. MEBRAHITOM ASMELASH ${ }^{a,},{ }^{*}$ O. MAMAT ${ }^{b}$, \\ F. AHMAD ${ }^{b}$, A. K. PRASADA RAO ${ }^{a}$ \\ ${ }^{a}$ Faculty of Manufacturing Engineering, Universiti Malaysia Pahang, Pekan, Pahang, Malaysia \\ ${ }^{b}$ Universiti Teknologi PETRONAS, Bandar Seri Iskandar, 31750 Tronoh, Perak, Malaysia
}

Received: November 11, 2014; Revised: February 06, 2015; Accepted: February 26, 2015

(C) The Author(s) 2015. This article is published with open access at Springerlink.com

\begin{abstract}
The thermal shock and fatigue behavior of pressureless sintered $\mathrm{Al}_{2} \mathrm{O}_{3}-\mathrm{SiO}_{2}-\mathrm{ZrO}_{2}$ (ASZ) composites was studied. The influence of the thermal shock and fatigue on the strengthening response of ASZ has been investigated by measuring the strength retention and microstructural changes. The magnitude of the flexural strength and fracture of the ASZ has been compared with that of the monolithic $\mathrm{Al}_{2} \mathrm{O}_{3}$ (A) and $\mathrm{Al}_{2} \mathrm{O}_{3}-\mathrm{ZrO}_{2}$ (AZ) composites under the same experimental conditions. Results indicated that the ASZ composites possess the highest resistance against thermal shock and fatigue, in comparison with A and AZ. The improvements were attributed to the enhancement in the fracture toughness of ASZ and the presence of multi-phase reinforcement.
\end{abstract}

Keywords: ceramics; flexural strength; fracture toughness; pressureless sintering; thermal fatigue; thermal shock

\section{Introduction}

Ceramic based composites are considered one of the best candidates for high-temperature applications (e.g., in gas turbine engines), and are widely involved in thermal shock loading environments. Most ceramics show catastrophic drop in mechanical properties, such as flexural strength and elastic modulus after thermal shock above the critical temperature difference $\left(\Delta T_{\mathrm{c}}\right)$. This drastic drop in mechanical properties after the thermal shock has limited their wide applications at high temperatures [1,2].

The fundamental phenomena of the thermal shock

\footnotetext{
* Corresponding author.

E-mail: mebrahitoma@yahoo.com
}

resistance in ceramics occur when the isotropic thermal expansion is constrained and the localized temperature gradients are induced due to rapid temperature changes $[3,4]$. In general, owing to their poor thermal conductivity, ceramics are susceptible to thermal shock in the absence of external constrains due to temperature gradient. Upon rapid cooling, the surface of a high-temperature specimen is accompanied by surface tensile stresses due to the fact that the surface contracts more than the interior where is still relatively hot. As a consequence, the surface pulls the interior into compression and is itself pulled into tension.

Researches on ceramic based composites focus on the improvement and optimization of fracture toughness, strength, and thermal shock values through ductile metallic reinforcements [5-7]. Shi et al. [6] 
improved the mechanical and thermal shock resistance of alumina and $\mathrm{Al}_{2} \mathrm{O}_{3}-\mathrm{TiCo}$ composite due to the inclusion of ductile material cobalt. It was shown that the addition of a second and third phase particulates to alumina matrix improves the mechanical properties and thermal shock resistance. There is also extensive research work of non-metallic and non-oxide ceramic reinforcements used to improve the mechanical and thermal properties. For example, the composites such as $\mathrm{GZSA}\left(\mathrm{ZrB}_{2}-\mathrm{SiC}-\mathrm{AlN}\right)$ [8], ZSA ( $\left.\mathrm{ZrB}_{2}-\mathrm{SiC}-\mathrm{AlN}\right)$ [8], $\mathrm{ZrO}_{2}-\mathrm{AlON}$ [9], and $\mathrm{Si}_{3} \mathrm{~N}_{4}-\mathrm{TiC}$ [10] show an improved retained flexural strength (RFS) in comparison with the monolithic components of each respective composite as the thermal shock temperature increases. When the ceramic composite materials are facing a sudden temperature gradient, the transient thermal stress created around the body will induce a thermal shock which results in a subcritical crack growth phenomenon which reduces the flexural strength [11]. It was reported that the improvement in the mechanical and thermal properties is due to the resistance to crack initiation and propagation.

Alumina reinforced with oxide ceramic composites is a widely used material in the high-temperature structural applications. There are several studies on the thermal shock and fatigue properties of homogeneous alumina and its oxide reinforcements. Panda et al. [12] studied the thermal shock and fatigue behavior of $\mathrm{Al}_{2} \mathrm{O}_{3}$ and observed that the fatigue life sharply decreases with increased temperature cycle. In order to enhance the thermal properties of $\mathrm{Al}_{2} \mathrm{O}_{3}$, Askel [13] developed $\mathrm{Al}_{2} \mathrm{O}_{3}$-mullite composite where he improved its thermal shock resistance. Rendtorff et al. [11] experimentally studied the thermal shock resistance and fatigue of $\mathrm{ZrSiO}_{2}-3 \mathrm{Al}_{2} \mathrm{O}_{3} \cdot 3 \mathrm{SiO}_{2}$ composites with different composition and microstructure to compare with the theoretical parameters of critical temperature difference $\left(\Delta T_{\mathrm{c}}\right)$, crack resistance, and fracture toughness. In each case, it was observed that improvement in the thermal properties is achieved through enhancement of the mechanical properties. In this work, three oxide ceramic materials of specific composition were investigated for thermal shock and fatigue properties. The materials were $\mathrm{Al}_{2} \mathrm{O}_{3}, \mathrm{Al}_{2} \mathrm{O}_{3}-20 \mathrm{ZrO}_{2}$, and $\mathrm{Al}_{2} \mathrm{O}_{3}-10 \mathrm{SiO}_{2}-20 \mathrm{ZrO}_{2}$ produced through pressureless sintering. The results of thermal shock and fatigue behavior of the specific ceramic composites were analyzed and compared in terms of the microstructural and mechanical properties.

\section{Experimental procedure}

\section{1 Materials and processing}

In this research, commercially available micron size $\mathrm{Al}_{2} \mathrm{O}_{3}(90 \mu \mathrm{m}$, Taimei Chemicals Co., Ltd., Tokyo) and $3 \mathrm{~mol} \%$ magnesia stabilized tetragonal zirconia $\mathrm{MgO}-\mathrm{ZrO}_{2}(17 \mu \mathrm{m}$, Taimei Chemicals Co., Ltd., Tokyo) starting powders, as well as silica sand $\mathrm{SiO}_{2}$ $(6.6 \mu \mathrm{m})$ were used. The $\mathrm{SiO}_{2}$ ceramic was produced in the laboratory by the dry milling process from locally found silica sand around Tronoh, Perak, Malaysia. In order to prepare the composite mixtures, the constituent powders were weighed in a precision balance (Mettler Teldo, Switzerland) in the required proportions and mixed thoroughly. Three types of compositions were prepared: monolithic alumina $\left(\mathrm{Al}_{2} \mathrm{O}_{3}\right)$, binary $\left(\mathrm{Al}_{2} \mathrm{O}_{3}-20 \mathrm{ZrO}_{2}\right)$ composites, and $\mathrm{Al}_{2} \mathrm{O}_{3}-10 \mathrm{SiO}_{2}-20 \mathrm{ZrO}_{2}$ (ASZ) where the prefix numbers show the weight percentage of each particle powders. Wet ball milling (US stoneware, 764AVU) equipment was used for the mixing. In preparing the mix, it was ensured that the powder mix was evenly distributed. This was achieved through the use of a dispersant (alcohol) which helped in avoiding agglomeration. Polyvinyl alcohol (PVA) was used as a binding agent in the preparation.

The ball milled powders were oven dried at a temperature of $105^{\circ} \mathrm{C}$ for $30 \mathrm{~min}$, and crashed and sieved to a particle size $<63 \mu \mathrm{m}$. The prepared powder mix were then filled in a standard rectangular $(4 \mathrm{~mm} \times 6 \mathrm{~mm} \times 35 \mathrm{~mm})$ and circular (internal diameter $13.4 \mathrm{~mm}$ ) die cavities, and were cold pressed using a hydraulic press (Carver, PW190-60, USA) at $450 \mathrm{MPa}$. The cold-compacted pellets were then reaction sintered in electrical tube furnace, heated by graphite elements with a heating rate of $10{ }^{\circ} \mathrm{C} / \mathrm{min}$ to $600{ }^{\circ} \mathrm{C}$, and held at this temperature for $15 \mathrm{~min}$ to remove the binder constituent. They were then heated with the same rate to $900{ }^{\circ} \mathrm{C}$ and held again for $25 \mathrm{~min}$ for homogenization. The temperature was increased up to $1650{ }^{\circ} \mathrm{C}$, followed by soaking isothermally for $4 \mathrm{~h}$. Subsequently, the temperature was dropped to room temperature at a cooling rate of $20{ }^{\circ} \mathrm{C} / \mathrm{min}$.

\section{2 Thermal shock and fatigue test}

The thermal shock resistance of the composites was 
evaluated by water quenching technique as shown in Fig. 1. Standard test (ASTM C1171) method for quantitative measurement of the effect of thermal shock on refractories was applied [14]. The summary of the experimental parameters for both thermal cycle (fatigue) and thermal shock are shown in Table 1. The strength was measured by the difference in flexural strength or modulus of rupture (MOR) between un-cycled (as-received) specimens and the specimens subjected to thermal cycling. The reduction in structural continuity was measured by the difference in mechanical property before and after thermal cycling. The furnace temperature for thermal cycling was $950{ }^{\circ} \mathrm{C}$, and the water quenching temperature after soaking was $25{ }^{\circ} \mathrm{C}$.

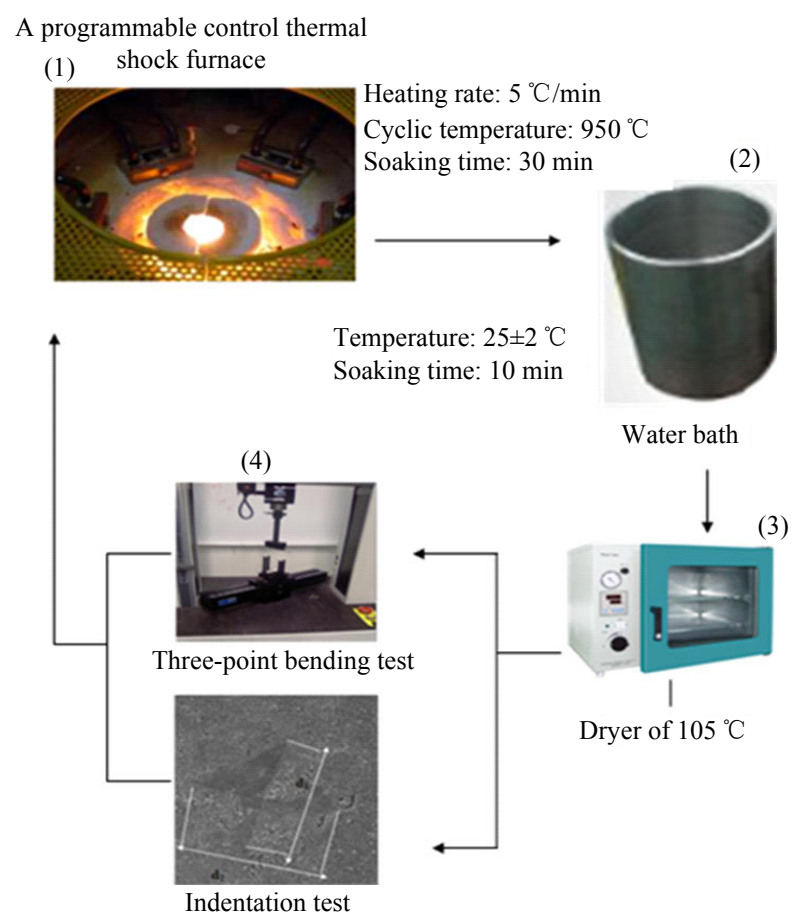

Fig. 1 Thermal shock resistance test using water quenching method.

Table 1 Parameters and methods for thermal cycle (fatigue) and thermal shock tests

\begin{tabular}{|c|c|c|c|c|}
\hline \multicolumn{5}{|c|}{ Thermal cycle (fatigue) test } \\
\hline $\begin{array}{c}\text { Cyclic } \\
\text { temperature } \\
\left({ }^{\circ} \mathrm{C}\right)\end{array}$ & $\begin{array}{c}\text { Dwelling or } \\
\text { soaking time } \\
\text { (min) }\end{array}$ & $\begin{array}{l}\text { Heating } \\
\text { rate } \\
\left({ }^{\circ} \mathrm{C} / \mathrm{min}\right)\end{array}$ & $\begin{array}{l}\text { Quenching water } \\
\text { temperature }\left({ }^{\circ} \mathrm{C}\right)\end{array}$ & $\begin{array}{l}\text { Fracture } \\
\text { toughness }\end{array}$ \\
\hline 950 & 30 & 5 & 25 & $\begin{array}{c}\text { Vickers } \\
\text { indentation } \\
\text { method }\end{array}$ \\
\hline \multicolumn{5}{|c|}{ Thermal shock test } \\
\hline$\Delta T^{*}\left({ }^{\circ} \mathrm{C}\right)$ & $\begin{array}{r}\text { Water } \mathrm{b} \\
\text { temperatu }\end{array}$ & $\begin{array}{l}\text { ath } \\
\left({ }^{\circ} \mathrm{C}\right)\end{array}$ & \multicolumn{2}{|c|}{ Flexural strength } \\
\hline $0-950$ & 25 & & 3-point bendil & g method \\
\hline
\end{tabular}

${ }^{*} \Delta T$ is the difference between heating and quenching temperatures.
To study the effect of number of cycles prior to failure, the experiment was done by heating the samples at a rate of $5{ }^{\circ} \mathrm{C} / \mathrm{min}$ up to $950{ }^{\circ} \mathrm{C}$ with a soaking time of $30 \mathrm{~min}$. This sample temperature was rapidly cooled by quenching in water till it attained room temperature.

In order to study the critical temperature change of the composite samples, thermal shock experiments were also performed in the programmable thermal shock furnace shown in Fig. 1(1). Specimens were placed into the preheated furnace and were held inside for $30 \mathrm{~min}$ before quenching by dropping into a bath of water $\left(25^{\circ} \mathrm{C}\right)$. Tests were carried out at temperature differences, $\Delta T$, between 250 and $950{ }^{\circ} \mathrm{C}$. The resistance of ceramics towards thermal shock was characterized using the critical temperature difference $\Delta T_{\mathrm{c}}$. It is the critical temperature difference at which the ceramics show a significant reduction in the retained strength upon cooling or heating. The $\Delta T_{\mathrm{c}}$ of the thermal shock temperature was identified corresponding to a reduction of $30 \%-50 \%$ of the flexural strength before thermal shock.

\section{3 Flexural strength}

The retained flexural strength (RFS) of the thermal shocked ceramics was measured by a 3-point bending method at room temperature, using a universal testing machine (Instron Model1185, Instron, USA). These tests were conducted on the specimen to each $\Delta T$ and chemical composition. The span length and cross-head speed were $25 \mathrm{~mm}$ and $0.1 \mathrm{~mm} / \mathrm{min}$, respectively. The value of the flexural strength reported was an average of three measurements for each of the quenching shock temperature difference $(\Delta T)$ as stated in the ASTM standard [14].

\section{4 Fracture toughness}

As-received and thermally loaded samples after 6 thermal cyclic shocks were compared. The fracture toughness was investigated as a possible criterion for quantifying the microstructural damage caused by the thermal cyclic loading. The microstructure and the resulting shape characteristics (especially the measured indent geometry) were used as input data for fracture toughness calculation. Fracture toughness measurement was performed by making an indentation on the samples first and then using the indentation fracture (IF) method, involving calculation of $K_{\mathrm{IC}}$ from measured crack lengths emanating from corners of 
indent diagonals shown in Fig. 2. $K_{\mathrm{IC}}$ calculations are based on relations proposed by various models. In this work however, fracture toughness for the samples was calculated using Eq. (1) derived by Anstis et al. [15] from a two-dimensional fracture mechanics analysis, as follows:

$$
K_{\mathrm{IC}}=0.016 \frac{P}{C_{0}^{3 / 2}}\left(\frac{E}{H}\right)^{1 / 2}
$$

where $P$ is the load $(\mathrm{N}) ; C_{0}(=d / 2+l)$ is the crack length from the center of the indent to the crack tip (m); $E$ is the Young's modulus (GPa); and $H$ is the Vickers hardness (GPa).

\subsection{X-ray diffraction and microstructure}

The samples were smoothly ground and polished using a $\mathrm{SiC}$ paste and cleaned. X-ray diffraction (XRD) analyses were carried out on a standard Philips diffractometer (XRD-Bruker AXS D8) operating at $30 \mathrm{~mA}$ and $40 \mathrm{kV}$ using $\mathrm{Cu} \mathrm{K} \alpha$ radiation. The scanning speed was $0.5\left(^{\circ}\right) / \mathrm{min}$. The microstructure of fracture surface of the composites was observed by field emission scanning electron microscopy (FESEM) and energy dispersive spectroscopy (EDS; Ziess Supra $55 \mathrm{VP}$ ) for elemental analysis.

\section{Results and discussion}

\section{1 Thermal shock}

Figure 3 shows the changes in flexural strength with respect to the increased thermal shock temperature $(\Delta T)$ of A, AZ, and ASZ composites. Three stages of flexural strength changes are observed as the quenching temperature increases. Around the initial temperature, the retained flexural strength is almost equal to the original, because the transient stress created is not strong enough to initiate crack or

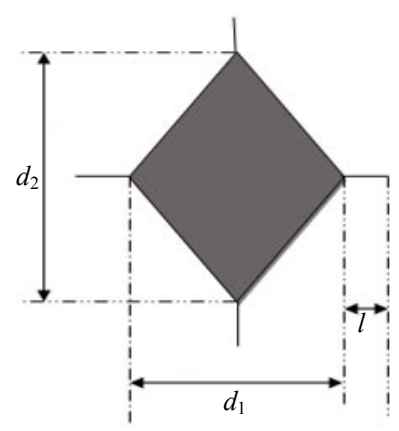

Fig. 2 Schematic crack generated by Vickers indenter.

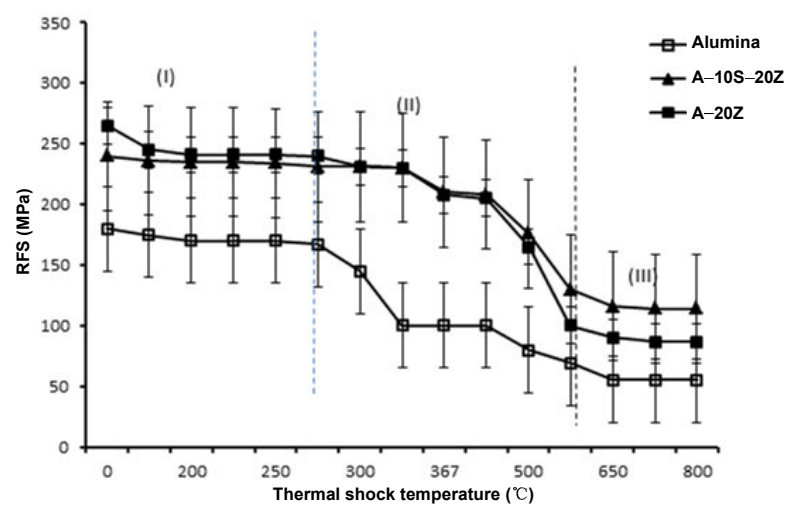

Fig. 3 Retained flexural strength versus shock temperature difference.

propagate the inherent crack in the specimen. In the second stage, there is a fast drop in flexural strength over a long temperature range, in which the critical temperature difference $\left(\Delta T_{\mathrm{c}}\right)$ is determined. In the third sage, there is steady change of lower retained flexural strength where subcritical crack would be expected to grow. The ASZ composites show a critical temperature difference $\left(\Delta T_{\mathrm{c}}\right)$ around $520{ }^{\circ} \mathrm{C}$, whereas $\mathrm{AZ}$ and monolithic A ceramics are measured around $480{ }^{\circ} \mathrm{C}$ and $290{ }^{\circ} \mathrm{C}$, respectively. This shows the ASZ composites developed possess greater resistance to thermal shock than AZ and A. The improvement can be attributed to the addition of the silica and zirconia which results in three component phases of alumina, zirconia, and mullite as shown in the XRD graph of the composites in Fig. 4. From our previous study [16,17], it was reported that major phases on the surface layer of the ASZ are alumina, zirconia, mullite, and residual few amorphous silica. It was considered that the starting material $\mathrm{SiO}_{2}$ reacts almost completely with $\mathrm{Al}_{2} \mathrm{O}_{3}$ to form mullite in the stoichiometric reaction equation below. The XRD pattern shows intense sharp

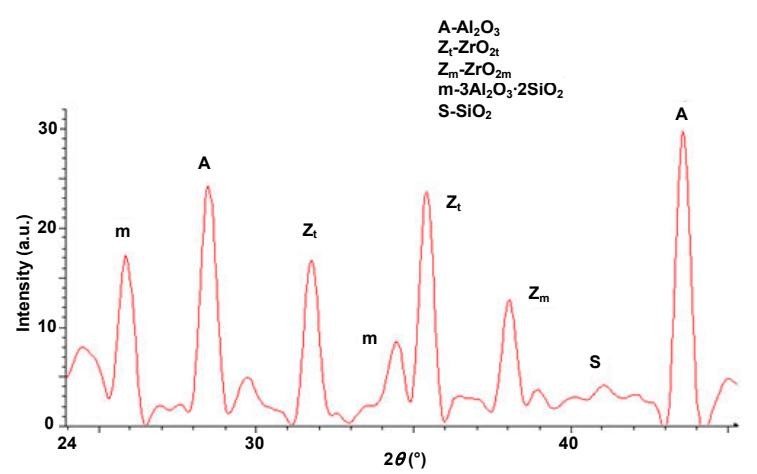

Fig. 4 XRD pattern of the sintered A-10S-20Z sample [8]. 
peaks as well indicating good crystallinity of ASZ based system for the compositions studied. The synthesis reaction in the sintering process is summarized as follows [18]:

$$
\begin{aligned}
& 4 \mathrm{Al}_{2} \mathrm{O}_{3}+2 \mathrm{SiO}_{2}+(1+x) \mathrm{ZrO}_{2} \rightarrow \\
& 3 \mathrm{Al}_{2} \mathrm{O}_{3} \cdot 2 \mathrm{SiO}_{2}+\mathrm{Al}_{2} \mathrm{O}_{3}+x \mathrm{ZrO}_{2}
\end{aligned}
$$

Figures 5(a) and 5(b) show the microstructure of $\mathrm{AZ}$ and ASZ composites, respectively, indicating the phases as $\mathrm{A}, \mathrm{M}$, and $\mathrm{Z}$ designated for alumina, mullite, and zirconia respectively. One of the possible explanations for the increase in thermal shock resistance of the ASZ composites is that the grain shape of mullite in A-10S-20Z develops an elongated and short fiber like morphology as shown by the arrows in Fig. 5(b). The interlock of elongated grains can hinder the grain boundary sliding, so that by decreasing the strain rate it would contribute for the higher thermal shock resistance of the material. Secondly, tri-component structure can limit the grain growth and create new interfaces which do not exist in the binary AZ and A composites [17]. Thus the ASZ structure interface may have different grain boundary mobility which contributes for a refined grain size of the alumina matrix. The refined grain would play an important role in the improvement of mechanical properties and thermal shock resistance of ASZ composites. Zhang et al. [19] reported that the thermal shock resistance could be improved by decreasing grain size or increasing the bulk density. The presence of $\mathrm{ZrO}_{2}$ and mullite particles as a triple particle system as well leads to a reduction in porosity and higher flexural strength [18] which contributes for improved thermal shock resistance of $\mathrm{Al}_{2} \mathrm{O}_{3}$ ceramic.

\section{2 Thermal cyclic loading}

When ceramic materials are subjected to a thermal cyclic environment, a progressive crack initiation and final fracture will occur. Fracture toughness is an important factor to evaluate the fracture behavior of ceramic composites after thermal cycle. In this paper,

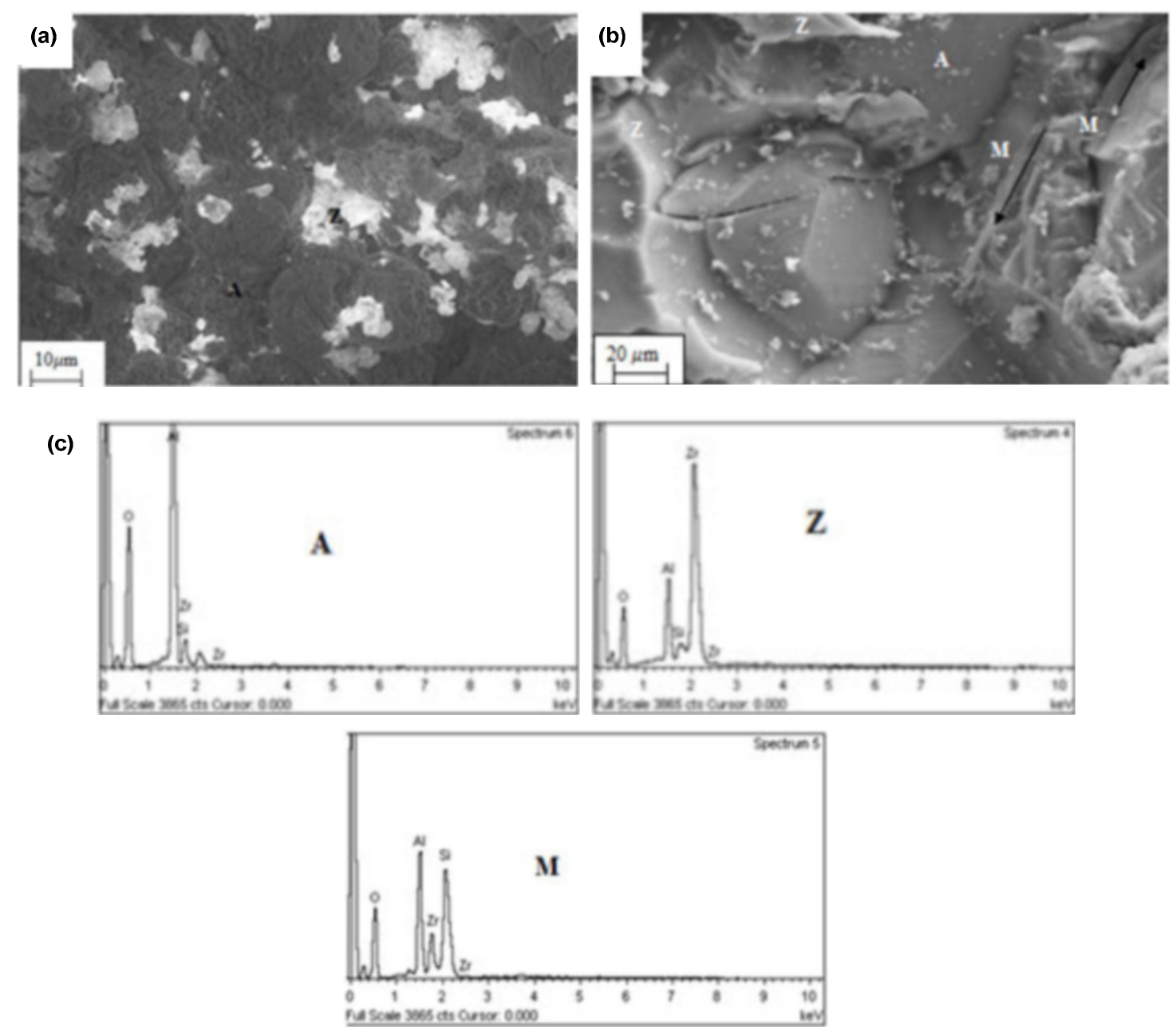

Fig. 5 (a) and (b) FESEM micrographs and (c) EDS spot scan of fractured ASZ composites. 
indentation method was used to measure the resistance to fracture after each thermal cycle by measuring the indent crack length as shown in Fig. 6. The indents were made at different thermal cyclic loads and the length was measured as illustrated in Section 2.3.

Table 2 shows the fracture toughness values of each three samples as-sintered after 6 thermal cycles. The facture toughness values show a decrease of $10.81 \%$, $24.65 \%$, and $28.5 \%$ of those of the as-sintered samples A-10S-20Z, A-20Z, and $\mathrm{Al}_{2} \mathrm{O}_{3}$ composites, respectively. It is clearly observed that the ASZ composites show a lower reduction in fracture toughness than the binary and monolithic. This is mainly attributed to the improvement of fracture

Table 2 Fracture toughness values after 6 thermal cycles

\begin{tabular}{ccc}
\hline $\begin{array}{c}\text { Sample } \\
\text { type }\end{array}$ & $\begin{array}{c}\text { As-sintered fracture } \\
\text { toughness } \\
\left(\mathrm{MPa} \cdot \mathrm{m}^{1 / 2}\right)\end{array}$ & $\begin{array}{c}\text { Fracture toughness value after 6 } \\
\text { thermal cycles }\left(\mathrm{MPa} \cdot \mathrm{m}^{1 / 2}\right)\end{array}$ \\
\hline $\mathrm{Al}_{2} \mathrm{O}_{3}$ & $0.8 \pm 0.21$ & $0.57 \pm 0.21$ \\
$\mathrm{AZ}$ & $1.75 \pm 0.6$ & $1.565 \pm 0.6$ \\
$\mathrm{ASZ}$ & $2.39 \pm 0.7$ & $2.138 \pm 0.7$ \\
\hline
\end{tabular}

toughness in ASZ composites. The mechanisms of fracture improvements in the A-10S-20Z composites are well discussed in our previous research works [17]. An improvement in fracture toughness contributes for the higher resistance to facture damage due to thermal fatigue. This experimental result verifies the classical thermal shock empirical models established by Hasselman $[9,20]$. One of the models is regarding the thermal stress fracture resistance parameters $R$ and $R^{\prime \prime}$, which states that thermal shock resistance of ceramic composites could be improved by increasing fracture toughness $\left(K_{\mathrm{IC}}\right)$ and flexural strength $(\sigma)$ shown in Eqs. (2) and (3), where $E, \alpha, R^{\prime \prime}, \gamma$, and $v$ represent Young's modulus, coefficient of thermal expansion, thermal damage resistance, fracture surface energy, and Poisson's ratio of the material, respectively.

$$
\begin{gathered}
R=\sigma(1-v) /(E \alpha) \\
R^{\prime \prime}=\frac{E \gamma}{\sigma^{2}(1-v)} \approx\left(K_{\mathrm{IC}} / \sigma\right)^{2} /(1-v)
\end{gathered}
$$

$R$ (the resistance to thermal shock fracture for brittle ceramic materials when higher temperature is applied)
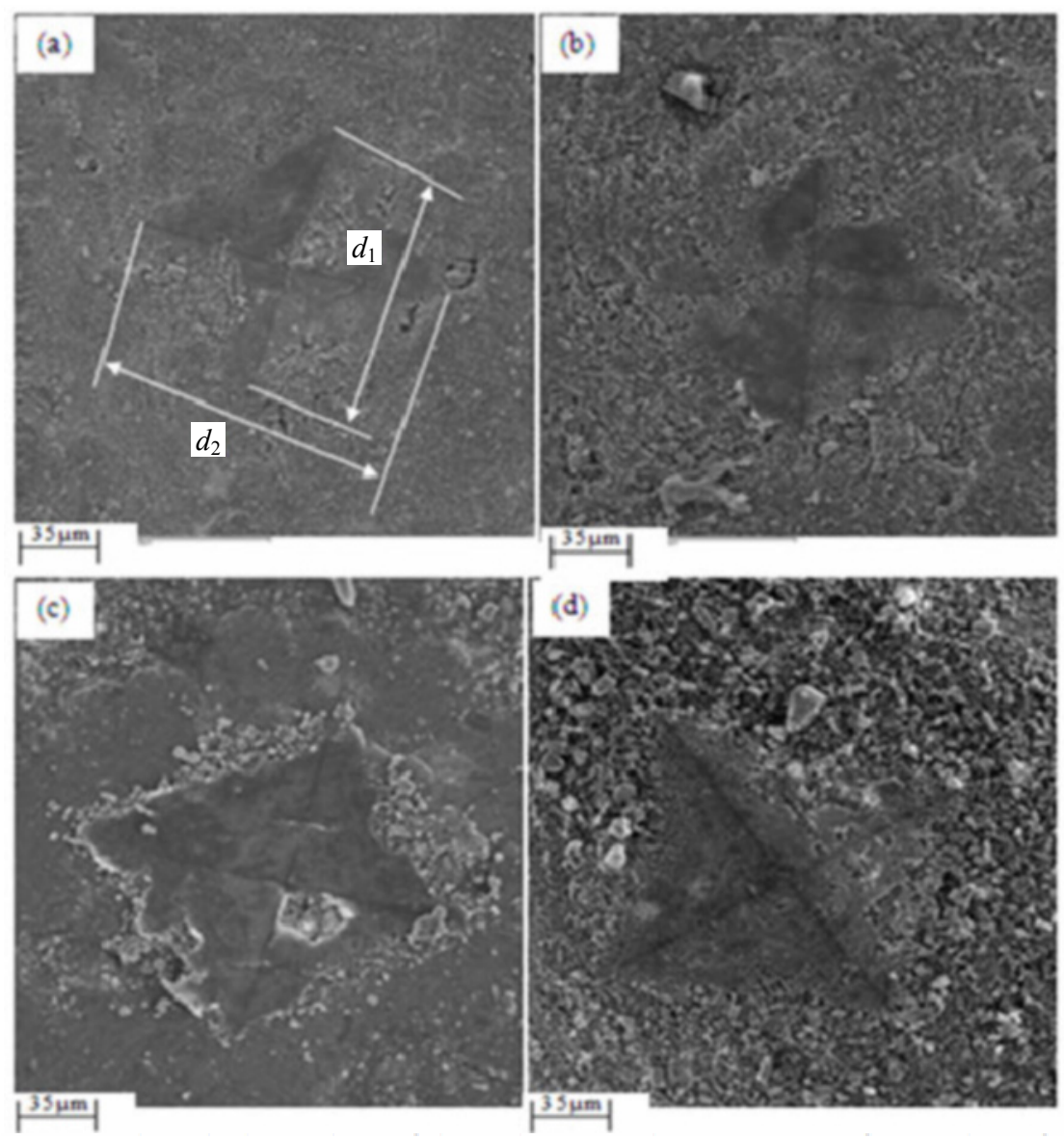

Fig. 6 Sample micro indentation of the $\mathrm{Al}_{2} \mathrm{O}_{3}-10 \mathrm{SiO}_{2}-20 \mathrm{ZrO}_{2}$ after a series of thermal shock cycles: (a) 4th cycle, (b) 5th cycle, (c) 6th cycle, and (d) 7th cycle. 
and $R^{\prime \prime}$ (the resistance to catastrophic crack propagation under critical temperature difference) are the parameters which have direct correlation with the critical temperature difference $\left(\Delta T_{\mathrm{c}}\right)$ of the materials used in this research for which we use as an analogy to ascertain the improved resistance to thermal cyclic loading for the ASZ composites.

The fact that the presence of ziroconia and mullite phases in the ASZ composites improves the thermal properties can be explained as follows. Figure 7 shows typical FESEM fracture micrographs of a pure $\mathrm{Al}_{2} \mathrm{O}_{3}$, A-20Z, and A-10S-20Z samples after 6 cycles of thermal shock tests at $950{ }^{\circ} \mathrm{C}$. It is shown that the fracture of pure alumina after thermal shock tests basically exhibits a fracture surface with cleavage (Fig. 7(a1)) and its magnified crack propagation looks straight as the thermal stress is too high to resist (Fig. 7(a2)). With the addition of micron-sized zirconia particles which lead to a tougher composite, the crack deflection and branching tend to occur frequently as indicated by the arrows in Figs. 7(b) and 7(c). Most importantly, the ASZ composites are more resistant for thermal shock due to the toughening effect of the zirconia and the shorter length needle like mullite particles as shown in Fig. 5, which lead to some pull-out and crack deflection as shown in Fig. 7(c). As Tancret et al. [21] reported, a successful improved facture toughness and thermal fatigue resistant composites were achieved due to the deflection of the propagating crack along the interface between the matrix and reinforcement. Zhao et al. [22] also found out the mechanisms of crack branching and deflection that occur at the interfaces between the two phases and impede the crack growth. It may be also due to the pinning role of the added zirconia and mullite particles [17] that locate at grain boundaries or triple junctions of alumina grains as shown in Fig. 4(c). These indicate that the added micron-sized silica and zirconia particles play an important role to improve the thermal shock resistance of alumina ceramic.

The FESEM observation from the cross sections of the AZ and ASZ composites after 6 cycles also shows that more degradation happens in the binary AZ samples. This degradation can be seen from the zirconia phase scattered (Fig. 7(b)), located by the brighter spot in the microstructure and pulled due to the thermal stress. In the A-10S-20Z composites (Fig. 7(c)), there is better microstructural integrity where the zirconia can be seen well stabilized. The grains seem to be structurally stable and the cracks are deflected in different direction. This implies that the ASZ composites have better fracture toughness than the binary (A-20Z). The availability of $\mathrm{SiO}_{2}$ and mullite phases around the grain boundaries and the
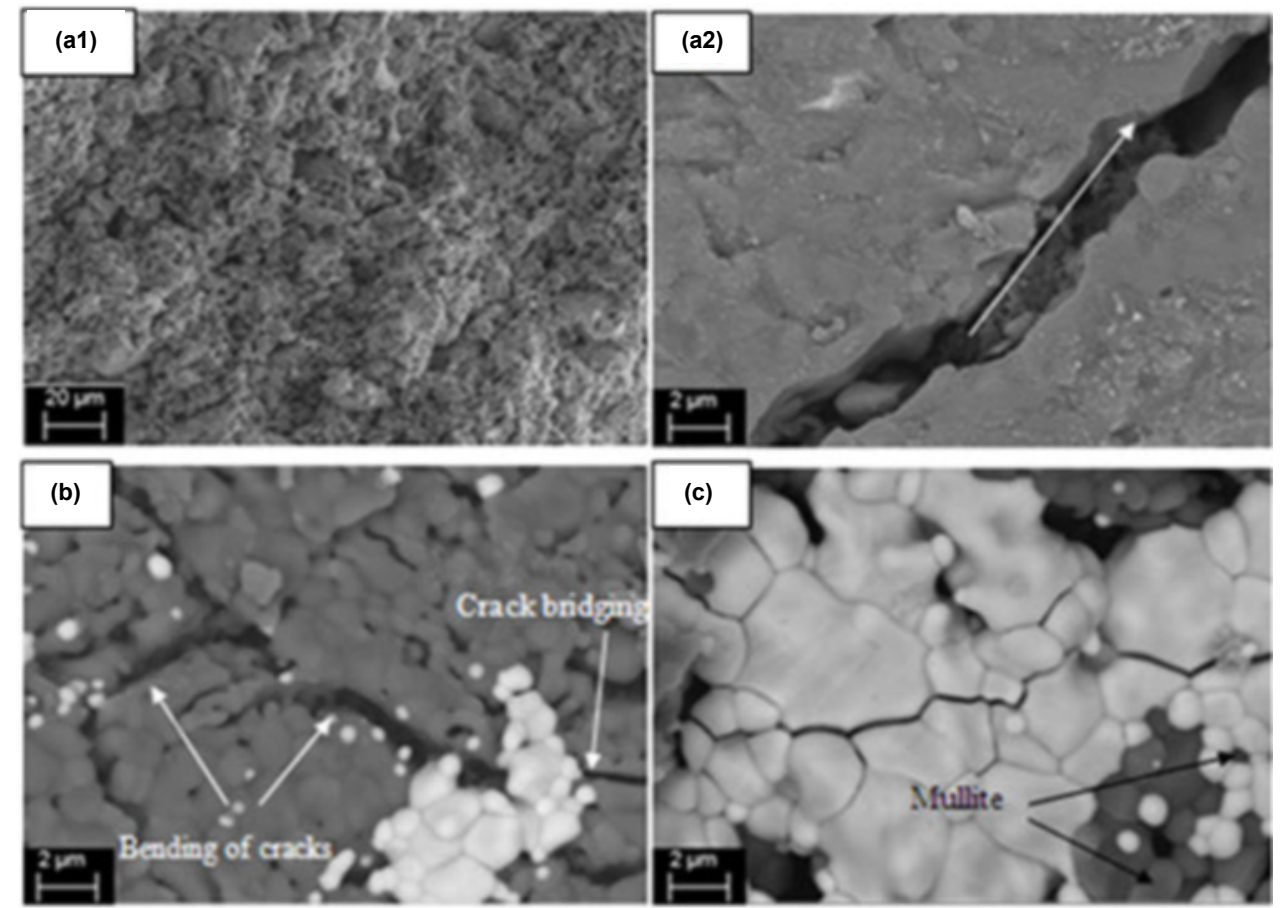

Fig. 7 FESEM micrographs of thermal shock induced crack propagation on fractured surfaces at the 6th cycle: (a1) $\mathrm{Al}_{2} \mathrm{O}_{3}$, (a2) $\mathrm{Al}_{2} \mathrm{O}_{3}$ (magnified), (b) A-20Z, and (c) A-10S-20Z. 
synergic effect could also be the reason for better thermal shock properties.

The improved thermal shock resistance of ASZ composites could also be partly attributed to the superior thermal properties of the added particles. The average coefficient of thermal expansion of mullite and $\mathrm{ZrO}_{2}$ are $5.4 \times 10^{-6}\left({ }^{\circ} \mathrm{C}\right)^{-1}$ and $10.3 \times 10^{-6}\left({ }^{\circ} \mathrm{C}\right)^{-1}$, respectively [13]. Furthermore, the thermal conductivity of mullite and alumina are $6 \mathrm{~W} \cdot \mathrm{m}^{-1} \cdot \mathrm{K}^{-1}$ and $18 \mathrm{~W} \cdot \mathrm{m}^{-1} \cdot \mathrm{K}^{-1}$, respectively [13]. Thus, the difference in the thermal properties of the $\mathrm{SiO}_{2}, \mathrm{ZrO}_{2}$, and alumina could also have an effect on the thermal shock behavior of ASZ composites. Mozquita et al. [23] showed that mullite improves the thermal shock behavior of dense alumina ceramics owing to its low Young's modulus and coefficient of thermal expansion. However, additional critical studies are needed to verify the effect of thermal and electrical properties of the reinforcing particles on the alumina matrix composite.

\section{Conclusions}

The thermal shock resistance for $\mathrm{Al}_{2} \mathrm{O}_{3}-\mathrm{SiO}_{2}-\mathrm{ZrO}_{2}$ was found to be higher than the monolithic $\mathrm{Al}_{2} \mathrm{O}_{3}$ and binary $\mathrm{Al}_{2} \mathrm{O}_{3}-\mathrm{ZrO}_{2}$ composites. The critical thermal shock temperature difference $\left(\Delta T_{\mathrm{c}}\right)$ of the $\mathrm{Al}_{2} \mathrm{O}_{3}$ monolithic, binary AZ composites, and ASZ composites were $290{ }^{\circ} \mathrm{C}, 480{ }^{\circ} \mathrm{C}$, and $520{ }^{\circ} \mathrm{C}$, respectively. Such improved thermal shock resistance and microstructural stability at high temperature for the ASZ material were attributed to the significant improvement of the fracture toughness by the tri-component composite system. The thermal fatigue resistance of the $\mathrm{Al}_{2} \mathrm{O}_{3}-\mathrm{SiO}_{2}-\mathrm{ZrO}_{2}$ composites was also better than the monolithic and binary composites. More importantly, the results in this work indicated that the $\mathrm{SiO}_{2}$ (silica sand) addition results in mullite, contributing for the high resistance to thermal shock. The thermal shock results showed an interesting phenomenon that A-20Z and A-10S-20Z composites trend a better thermal shock resistance than monolithic $\mathrm{Al}_{2} \mathrm{O}_{3}$ as the quenching temperature increases.

Open Access: This article is distributed under the terms of the Creative Commons Attribution License which permits any use, distribution, and reproduction in any medium, provided the original author(s) and the source are credited.

\section{References}

[1] Wang H, Singh RN. Thermal shock behaviour of ceramics and ceramic composites. Int Mater Rev 1994, 39: 228-244.

[2] Mebrahitom Asmelash G, Mamat O. Processing and characterisation of $\mathrm{Al}_{2} \mathrm{O}_{3} \mathrm{SiO}_{2} \mathrm{ZrO}_{2}$ composite material. International Journal of Microstructure and Materials Properties 2012, 7: 64-76.

[3] Shackelford JF, Doremus RH. Ceramic and Glass Materials: Structure, Properties and Processing. New York: Springer, 2008.

[4] Manson SS. Behavior of materials under conditions of thermal stress. National Advisory Committee for Aeronautics (NACA) report 1170, 1953. http://naca.central. cranfield.ac.uk/reports/1954/naca-report-1170.pdf.

[5] Fahrenholtz WG, Ellerby DT, Loehman RE. $\mathrm{Al}_{2} \mathrm{O}_{3}-\mathrm{Ni}$ composites with high strength and fracture toughness. $J$ Am Ceram Soc 2000, 83: 1279-1280.

[6] Shi R, Li J, Wang D, et al. Mechanical properties and thermal shock resistance of $\mathrm{Al}_{2} \mathrm{O}_{3}-\mathrm{TiC}-\mathrm{Co}$ composites. J Mater Eng Perform 2009, 18: 414-419.

[7] Sbaizero O, Pezzotti G. Influence of molybdenum particles on thermal shock resistance of alumina matrix ceramics. Mat Sci Eng A 2003, 343: 273-281.

[8] Wang Y, Liang J, Han W, et al. Mechanical properties and thermal shock behavior of hot-pressed $\mathrm{ZrB}_{2}-\mathrm{SiC}-\mathrm{AlN}$ composites. J Alloys Compd 2009, 475: 762-765.

[9] Zhang N, Zhao XJ, Ru HQ, et al. Thermal shock behavior of nano-sized $\mathrm{ZrN}$ particulate reinforced $\mathrm{AlON}$ composites. Ceram Int 2013, 39: 367-375.

[10] Tian C, Liu N, Lu M. Thermal shock and thermal fatigue behavior of $\mathrm{Si}_{3} \mathrm{~N}_{4}-\mathrm{TiC}$ nano-composites. Int J Refract Met H 2008, 26: 478-484.

[11] Rendtorff NM, Garrido LB, Aglietti EF. Thermal shock resistance and fatigue of zircon-mullite composite materials. Ceram Int 2011, 37: 1427-1434.

[12] Panda PK, Kannan TS, Dubois J, et al. Thermal shock and thermal fatigue study of alumina. J Eur Ceram Soc 2002, 22: $2187-2196$

[13] Aksel C. The influence of zircon on the mechanical properties and thermal shock behaviour of slip-cast alumina-mullite refractories. Mater Lett 2002, 57: 992-997.

[14] ASTM International. ASTM C1171-05 Standard test method for quantitatively measuring the effect of thermal shock and thermal cycling on refractories. West Conshohocken, PA: ASTM International, 2011.

[15] Anstis GR, Chantikul P, Lawn BR, et al. A critical evaluation of indentation techniques for measuring fracture toughness: I, direct crack measurements. J Am Ceram Soc 1981, 64: 533-538.

[16] Mebrahitom Asmelash G, Mamat O, Ahmad F. Investigation on the effect of silica sand addition in densification of $\mathrm{Al}_{2} \mathrm{O}_{3}-\mathrm{SiO}_{2}-\mathrm{ZrO}_{2}$ composite. J Ceram Process Res 2013, 14: 22-26.

[17] Mebrahitom Asmelash G, Mamat O, Ahmad F. Toughening mechanisms of $\mathrm{Al}_{2} \mathrm{O}_{3}-\mathrm{SiO}_{2}-\mathrm{ZrO}_{2}$ composite materials. Ceram-Silikaty 2012, 56: 360-366. 
[18] Mebrahitom Asmelash G, Mamat O. Pressureless sintering and characterization of $\mathrm{Al}_{2} \mathrm{O}_{3}-\mathrm{SiO}_{2}-\mathrm{ZrO}_{2}$ composite. Defect and Diffusion Forum 2012, 329: 113-128.

[19] Zhang HB, Zhou YC, Bao YW, et al. Abnormal thermal shock behavior of $\mathrm{Ti}_{3} \mathrm{SiC}_{2}$ and $\mathrm{Ti}_{3} \mathrm{AlC}_{2}$.J Mater Res 2006, 21: 2401-2407.

[20] Hasselman DPH. Unified theory of thermal shock fracture initiation and crack propagation in brittle ceramics. $\mathrm{J} \mathrm{Am}$ Ceram Soc 1969, 52: 600-604.

[21] Tancret F, Monot I, Osterstock F. Toughness and thermal shock resistance of $\mathrm{YBa}_{2} \mathrm{Cu}_{3} \mathrm{O}_{7-x}$ composite superconductors containing $\mathrm{Y}_{2} \mathrm{BaCuO}_{5}$ or $\mathrm{Ag}$ particles. Mat Sci Eng A 2001, 298: 268-283.

[22] Zhao XJ, Ru HQ, Chen DL, et al. Thermal shock behavior of nano-sized $\mathrm{SiC}$ particulate reinforced $\mathrm{AlON}$ composites. Mat Sci Eng B 2012, 177: 402-410.

[23] Mezquita S, Uribe R, Moreno R, et al. Influence of mullite additions on thermal shock resistance of dense alumina materials. Part 2: Thermal properties and thermal shock behaviour. Adv Appl Ceram 2001, 100: 246-250. 